\title{
PREDICTED PERFORMANCE OF THE INVERTED JOINED WING SCALED DEMONSTRATOR
}

\author{
Mateusz LIS ${ }^{1}$, Cezary GALINSKI ${ }^{2}$ \\ Institute of Aviation, al. Krakowska 110/114, 02-256 Warsaw, Poland

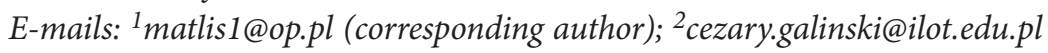

Received 12 March 2014; accepted 4 May 2015

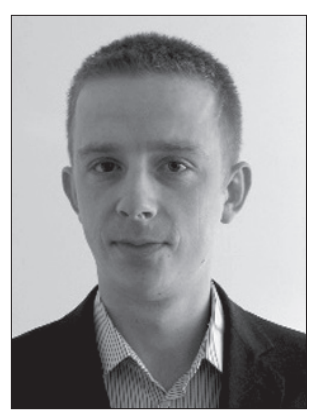

\section{Mateusz LIS}

Education: BSc (2006-2010), MSc (2010-2011) in the field of Aerospace Engineering with a major in aircraft structures, Warsaw University of Technology, Poland.

Affiliations and functions: engineer in GECP, Poland.

Research interests: aircraft performance, flight dynamics and stability, flight testing, aircraft composite structures.

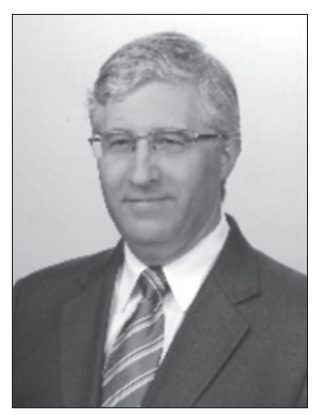

\section{Cezary GALINSKI}

Education: MSc (1986-1992), PhD (1992-1996), DSc (2007) in the field of Aerospace

Engineering, Warsaw University of Technology, Poland.

Affiliations and functions: associated professor and vice director of the Institute of Aviation, associated professor at Warsaw University of Technology, Poland.

Research interests: aircraft design.

Abstract. The aim of this paper is to present the performance analysis for an inverted joined wing aircraft demonstrator. Its configuration is said to offer lower drag in comparison to conventional aircraft, resulting in $\mathrm{L} / \mathrm{D}$ ratio improvement and better performance in general. Moreover, the solution with wings inverted, i.e. with the front wing located above the aft wing, seems to give an even better L/D ratio for a wider range of angles of attack. This paper aims at presenting an aeroplane's performance analysis, beginning from the determination of fundamental aircraft aerodynamic characteristics on the basis of wind tunnel tests, to the assessment of powered aircraft characteristics. Such an analysis will answer the question whether the proposed propulsion unit is suitable in this specific case, which means that it will determine if the climb ratio and maximum endurance are adequate. It is crucial to assess these factors before flight tests are initiated as they have a direct influence on the safety of the aeroplane. If the results of the analysis show that the current propulsion unit is not adequate, another one would be proposed taking into account that the maximum take-off weight cannot exceed $25 \mathrm{~kg}$, as defined by civil regulations. Finally, several types of mission profiles are to be planned with great attention to maximum flight endurance and the energy required in batteries that needs to be reserved for emergency situations.

Keywords: joined wing, flight demonstrator, flight performance, mission profile, flight testing, electric propulsion.

\section{Introduction}

The joined wing aeroplane configuration, also known as the box wing, rhomboid or diamond wing is considered as a set of two lifting surfaces connected directly to each other or with wing tip vertical plates. Depending on the

location of the lifting surfaces, it can be either positively or negatively staggered, or unstaggered, as shown in Figure 1. The latter configuration has been investigated for the first time by Prandtl (1924). The studies described 

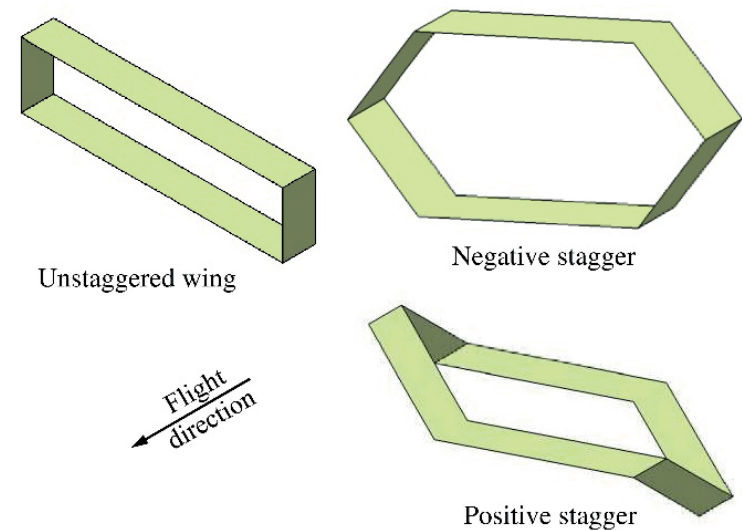

Fig. 1. Various configurations of a joined wing

previously showed that the box wing concept is superior in terms of minimum induced drag among other configurations, such as monoplane, biplane and triplane. A comparison of different configurations is presented in Figure 2, which shows that the box wing configuration offers a significant reduction of induced drag in comparison to the monoplane wing; however, it is strongly dependent on the system's height and can be estimated at $32 \%$ for a height ratio of 0.2 . Many other concepts, for example a wing equipped with winglets, side plates or U-shape wings have been investigated and described in (Kroo 2005).

According to (Frediani 2005; Kroo 2005), the induced drag of a typical commercial aeroplane accounts for up to $40 \%$ of the total cruise drag and becomes even more significant at low speeds, when it can reach up to $80 \%$ of the total aeroplane drag. The total drag for an aeroplane in level flight can be given by equation (1) (Perkins, Hage 1949):

$$
D=\frac{1}{2} C_{D 0} \rho S \cdot V^{2}+\frac{2 W^{2}}{\rho b^{2} \pi e} \cdot \frac{1}{V^{2}},
$$

where:

$-C_{D 0}$ is the minimum drag coefficient;

$-\rho$ is the air density at sea level, $1.225 \mathrm{~kg} / \mathrm{m}^{3}$;

$-S$ is the wing area, $\mathrm{m}^{2}$;

- $V$ is the airspeed, $\mathrm{m} / \mathrm{s}$;

- $W$ is the aeroplane weight, $\mathrm{N}$;

$-b$ is the wingspan, $\mathrm{m}$;

$-e$ is the Oswald efficiency factor.

The first term is defined as parasite drag, and the second term - as induced drag. This expression is very valuable, as it gives a brief insight into which parameters affect the total drag of the aeroplane; moreover, it can be used for a preliminary estimation of the drag value and the contribution of both components to the given airspeed.

The first concept of a staggered joined wing was patented in 1976 by Wolkovitch (1976), who in many

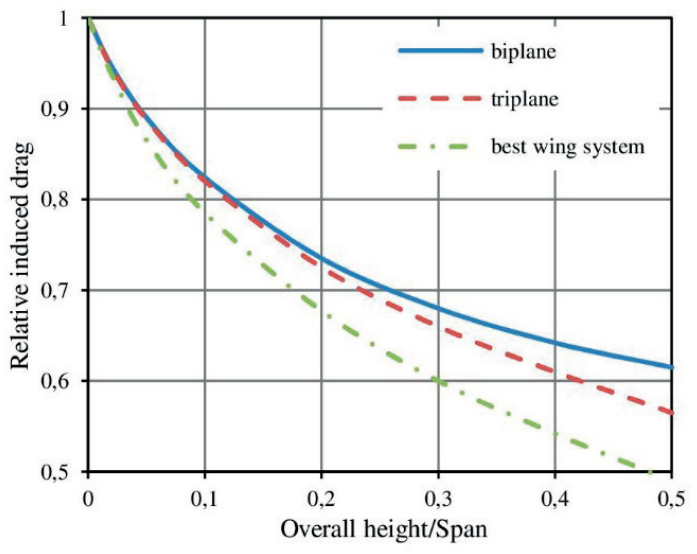

Fig. 2. Induced drag variation with increasing distance between the lifting surfaces for different non-planar concepts (Prandtl 1924).

other studies claimed that this configuration offers several advantages over conventional aeroplanes, such as weight savings, structure stiffness improvement, low induced and parasite drag, high $C_{\text {Lmax }}$, as well as improved stability and control characteristics (Wolkovitch 1986).

Despite the unstaggered box wing concept considered by Prandtl, Frediani (2005) found that, due to Munk's theorems (1923), induced drag is independent from the sweep angle; thus, Prandtl's theorem can also be extended to transonic and supersonic aircraft. In (Frediani 2005) studies on large passenger and cargo aeroplanes, medium size civil transport and small sport aeroplanes are presented. Apart from the several advantages listed before, he also found an improvement in the aeroplane's damage tolerance, better weight efficiency and increased fatigue life.

A more detailed conceptual design has been described in (Foong, Djojodihardjo 2012; Jemitola, Fielding 2012; Schiktanz 2011) and many others. Studies usually start with an initial estimation of the basic aeroplane parameters, which is then followed by a structural analysis and mass estimation for an assumed mission profile. An investigation of performance, stability and a rough estimation of costs and benefits are also presented. Final findings reveal that the joined wing is promising in terms of performance and operating costs but also generates some issues, among those the most important being the structural analysis complexity, due to the nonlinear effects and couplings between wings (Goraj 1997), aeroelasticity and the buckling effects on the rear wing, and stability issues.

Further studies concerning the joined wing described in (Mamla, Galinski 2009) suggested that the configuration with a positive stagger, i.e. with the aftswept top wing and forward swept lower wing is even more interesting. Despite being unpopular at the time, it turned out to be very advantageous. During a flight with high positive angles of attack, the wake from the front 
wing is far from the aft wing, due to which the former works in a steady and smooth airflow, which results in the fact that it is effective and not prone to stall. This finding resulted in the launch of a new project described in (Galinski 2013, 2014) the main purpose of which is to investigate the inverted joined wing aeroplane in terms of its performance, stability and controllability characteristics. The characteristics of the aeroplane explored so far have been briefly described in (Lis et al. 2014). The experience from previous similar programmes was used to perform the mission planning (Galinski 2004; Goraj 2004a, 2004b, 2005, 2012).

\section{Model description}

The basic geometrical dimensions of the aeroplane are shown in Figure 3, whilst Table 1 presents weight and wing surface data. The aeroplane is equipped with a pusher propeller driven by a brushless electric motor. The motor localization on the aft of the fuselage makes maintenance easy and, additionally, reduces the possibility of motor overheating. Moreover, such a solution allows for propulsion unit change into a different size/ output power or type unit (ducted fan, piston engine), which can be useful during prototype testing.

A three-point non-retractable undercarriage improves safety during taxing, take-off and landing. The aeroplane is a modular construction, with main components such as fuselage, front and rear wings, side plates and vertical stabilizer, connected to each other by screws and clasps. This layout significantly simplifies the aeroplane's transportation to the flight site and enables the replacement of components in case of damage or the necessity of configuration change. Its structure is mostly made of carbon and glass reinforced composites with a minor use of metals for highly loaded components (pins, screws, mounting brackets, etc.). A sandwich structure has been used for wing skins and fuselage surface to minimise aeroplane weight.

Table 1. Aeroplane weight and wing surface area

\begin{tabular}{|l|l|l|}
\hline Maximum take-off weight, $m_{T O W}$ & 25 & $\mathrm{~kg}$ \\
\hline $\begin{array}{l}\text { Front wing surface area } \\
\text { (reference area), } S_{F}\end{array}$ & 0,81 & $\mathrm{~m}^{2}$ \\
\hline $\begin{array}{l}\text { Rear wing surface area, } \\
S_{R}\end{array}$ & 0,54 & $\mathrm{~m}^{2}$ \\
\hline $\begin{array}{l}\text { Total surface area of wings, } \\
S\end{array}$ & 1,35 & $\mathrm{~m}^{2}$ \\
\hline $\begin{array}{l}\text { Wing loading, } \\
m_{T O W} / S\end{array}$ & 30,86 & $\mathrm{~kg} / \mathrm{m}^{2}$ \\
\hline
\end{tabular}

\section{Unpowered flight performance}

On the basis of the aerodynamic data obtained from wind tunnel tests (Lis 2014), the aeroplane's performance in a steady glide has been determined based on the methods presented in (Fiszdon 1961). Even though the

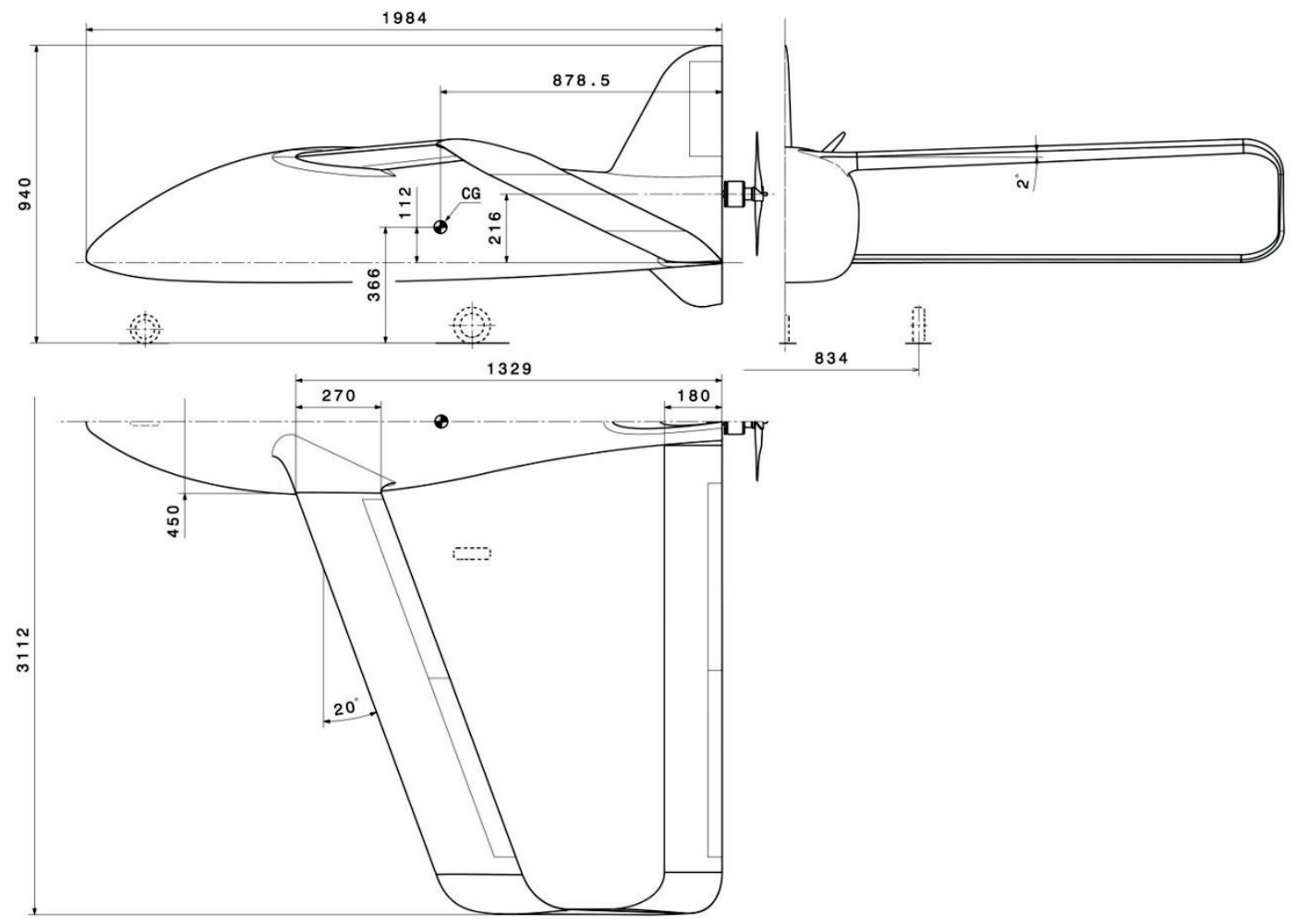

Fig. 3. The geometry of the MOSUPS joined wing flight demonstrator 
aeroplane is not intended for glide flight, except during the descending and landing approach phases, it is worth knowing its basic flight characteristics with power-off in case of emergency situations.

According to Figure 4 and Figure 5, which show the aeroplane's performance in a glide flight, the following conclusions can be drawn:

- the minimum speed equals $17.3 \mathrm{~m} / \mathrm{s}$ for a clean configuration (flaps not deployed) and can be reduced to less than $16.5 \mathrm{~m} / \mathrm{s}$ with flaps fully deployed (20 deg down). This suggests a low effectiveness of flaps, which is probably caused by the low relative flap chord, small deflection value, significant sweep angle and the simple plain type;

- for a clean configuration, the minimum sink rate is about $1.48 \mathrm{~m} / \mathrm{s}$ for an airspeed of $18,1 \mathrm{~m} / \mathrm{s}$, which corresponds to a 4.7 deg glide path. At this point the power required for steady level flight is minimal;

- the economical airspeed equals $19.1 \mathrm{~m} / \mathrm{s}$, when the aeroplane descends at $1.51 \mathrm{~m} / \mathrm{s}$ and the glide path angle is about $4.6 \mathrm{deg}$. This is the condition when the thrust required for level flight is the

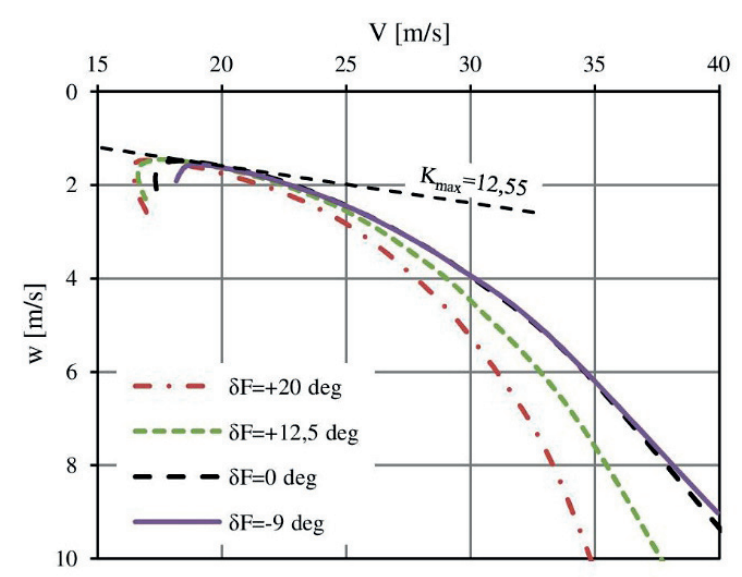

Fig. 4. Sink rate versus airspeed for various flap deflections

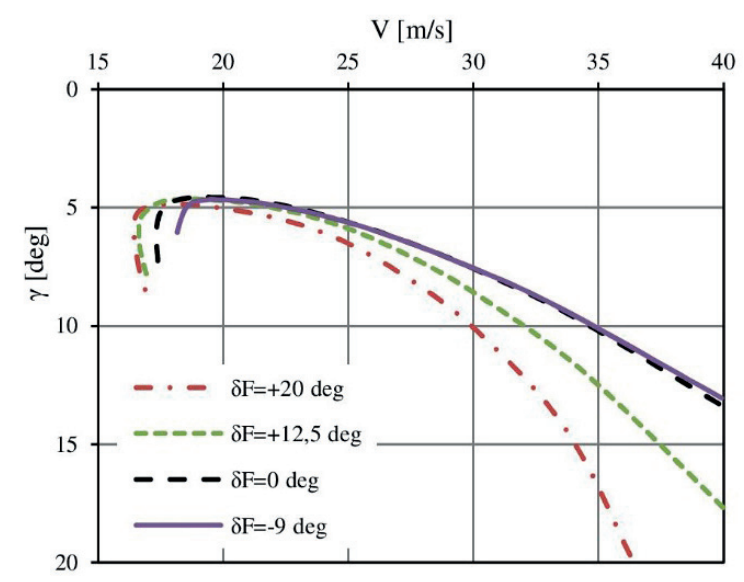

Fig. 5. Glide angle versus airspeed for various flap deflections lowest. It is worth pointing out that the airspeed is less than $2 \mathrm{~m} / \mathrm{s}$ higher than minimum (stall) speed, which can be very dangerous as it can easily lead to unintended stall in case of a gust from the bottom. This means that such a low speed should be avoided and that maximum gliding qualities will never be used;

- starting from an airspeed of about $30 \mathrm{~m} / \mathrm{s}$, the aeroplane's sink rate increases rapidly; therefore, coming back to the previous observation, it can be said that a practical glide airspeed would be within the range of $22-30 \mathrm{~m} / \mathrm{s}$ in a clean configuration.

\section{Propulsion system}

At the beginning of the project, it was assumed that electric propulsion will be used. A detailed description of the propulsion of the aeroplane can be found in (Bogdanski, Rodzewicz 2014). This reference describes all the steps undertaken during the process of propulsion system integration with the given aeroplane, i.e. preliminary CFD analyses, wind tunnel tests of several configurations and the final choice of the best configuration for a specific purpose. Together with the performance, the propulsion unit weight is a crucial factor defining its aeronautical usefulness.

Table 2. Basic technical data of the propulsion system components

\begin{tabular}{l|l|l}
\hline Motor: Turnigy RotoMax 1.60 & 37 & $\mathrm{~V}$ \\
\hline Voltage & 80 & $\mathrm{~A}$ \\
\hline Max. current & 849 & $\mathrm{~g}$ \\
\hline Weight & \multicolumn{2}{l}{} \\
\hline ESC: YEP 120 & 120 & $\mathrm{~A}$ \\
\hline Max. Cont. Current & 240000 & $\mathrm{rev} / \mathrm{min}$ \\
\hline Max. RPM & 100 & $\mathrm{~g}$ \\
\hline Weight & 39,6 & $\mathrm{~V}$ \\
\hline Battery: ANR26650M1-B 4p12s (48 cell) & \\
\hline Nom. Voltage & 9,6 & $\mathrm{Ah}$ \\
\hline Capacity & 200 & $\mathrm{~A}$ \\
\hline Max. Cont. Current & 4100 & $\mathrm{~g}$ \\
\hline Weight & \multicolumn{2}{|l}{} \\
\hline Propeller: Fiala 20x10 E &
\end{tabular}

The weight of the battery and thus its capacity has been defined by the maximum allowed take-off weight, which should not exceed $25 \mathrm{~kg}$ according to legal regulations. The following paragraphs are aimed at proving that the battery chosen and described in Table 2 is adequate for this case and allows for the performance of safe test flights of a reasonable duration. Figure 6 presents the characteristics of this propulsion unit obtained during wind tunnel tests. 


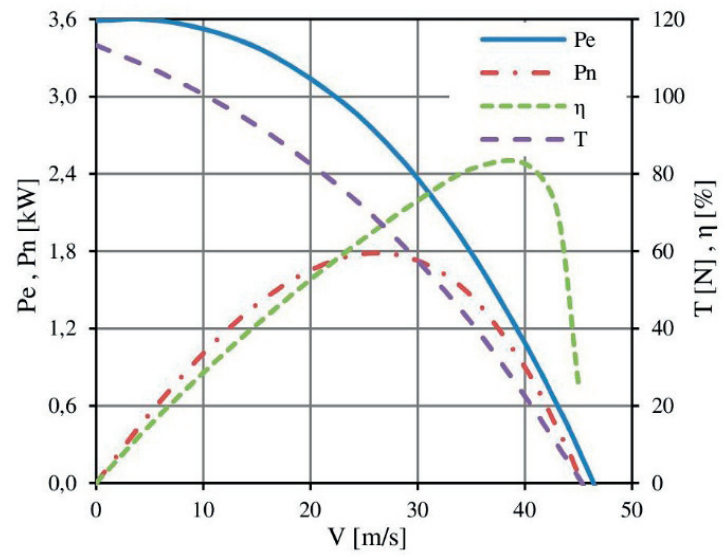

Fig. 6. Propulsion unit characteristics: $P_{\mathrm{e}}$ indicates motor electric power, $P_{N}$ - effective power, $\eta$ - total efficiency, $T$ - thrust

\section{Powered flight performance}

As stated in (Bogdanski, Rodzewicz 2014), wind tunnel tests have been carried out for different propulsion unit configurations. The final characteristics for the set of components listed in Table 2 have been determined as shown in Figure 6.

According to the data presented in the previous paragraphs, the aeroplane's powered flight performance has been calculated with the use of methods described in (Fiszdon 1961). The general assumptions were as follows:

- the thrust vector direction and velocity vector direction are consistent;

- the flight path angle is small, thus:

$\cos \theta \approx 1$ and $\sin \theta \approx \operatorname{tg} \theta \approx \theta$;

- due to thrust, the pitching moment is automatically compensated by the elevator deflection;

- a steady-state flight.

According to this method, the climb rate in a powered flight is given by the equation below:

$$
w=\frac{P_{N}-P_{R}}{W},
$$

where $P_{N}$ indicates the power available for a given airspeed $V$ and altitude $h, \mathrm{~W} ; P_{R}$ - the power required for a steady level flight, $W$.

The power available at sea level, $P_{N 0}$, was taken from Figure 7 and recalculated for several flight altitudes. It was assumed that the propeller revolution speed is independent from altitude, hence the following equation applies:

$$
P_{N}=P_{N 0} \cdot \sqrt{\frac{\rho_{0}}{\rho_{h}}},
$$

where $\rho_{h}$ indicates the air density at a flight level, $\mathrm{kg} / \mathrm{m}^{3}$.

The power required for a steady state level flight, $P_{R}$, equals the actual drag multiplied by airspeed and is given by the following equation:

$$
P_{R}=\frac{1}{2} \rho_{h} S C_{D} V^{3}
$$

The graphs of power available and power required versus airspeed for several altitudes are presented in Figure 7 and Figure 8, respectively.

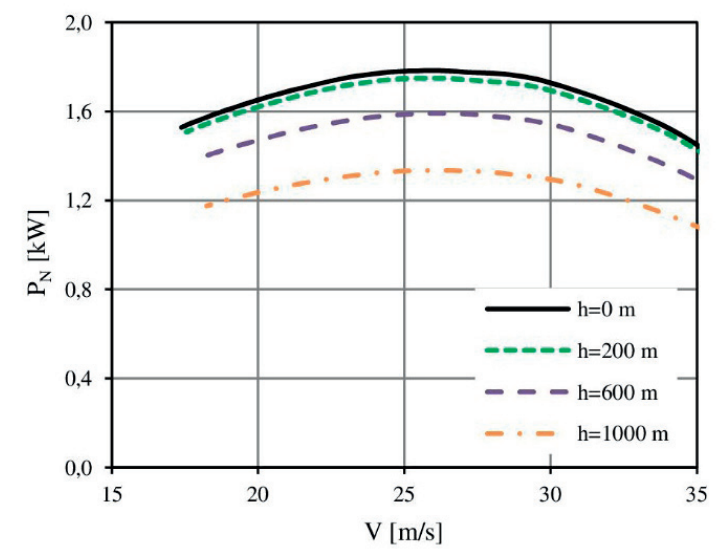

Fig. 7. Power available versus airspeed for several flight altitudes

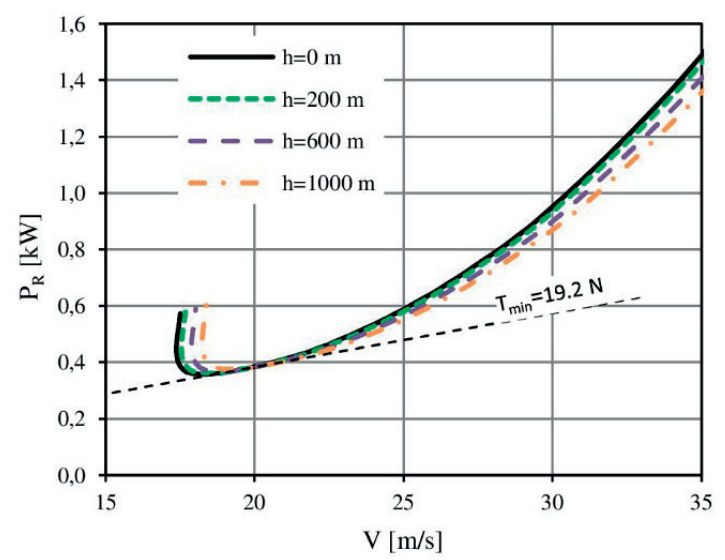

Fig. 8. Power required for level flight versus airspeed for several flight altitudes

As shown above, the minimum power required for a steady level flight at sea level equals $360 \mathrm{~W}$ for an airspeed of $18.1 \mathrm{~m} / \mathrm{s}$ and the minimum thrust equals 19.2 $\mathrm{N}$ for an airspeed of $19.1 \mathrm{~m} / \mathrm{s}\left(P_{R}=370 \mathrm{~W}\right)$. These points correspond to the characteristic points in the glide performance graphs, also see Figure 4 .

With the use of the equations and data already presented, the maximum climb rate calculations have been carried out and the results are presented in Figure 9 and Figure 10.

The most important conclusions that can be drawn from these figures are:

- maximum climb rate equals $5.3 \mathrm{~m} / \mathrm{s}$ for an airspeed of $22 \mathrm{~m} / \mathrm{s}$ at sea level and decreases to 3.6 $\mathrm{m} / \mathrm{s}$ at an altitude of $1000 \mathrm{~m}$. These values are quite high and seem to be sufficient for such an aeroplane type;

- maximum climb angle equals $16 \mathrm{deg}$ for an airspeed of $18.1 \mathrm{~m} / \mathrm{s}$ at sea level and decreases to approximately $10 \mathrm{deg}$ at an altitude of $1000 \mathrm{~m}$. 


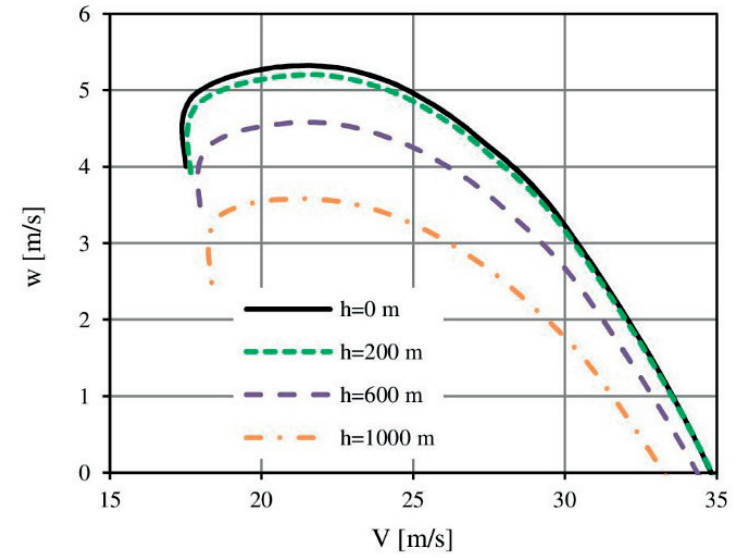

Fig. 9. Maximum climb rate versus airspeed for several flight altitudes

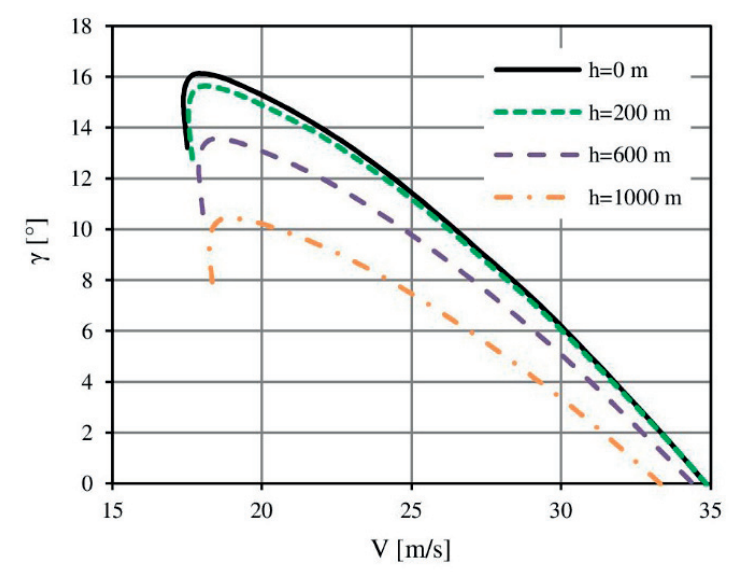

Fig. 10. Maximum climb angle versus airspeed for several flight altitudes

These values are also reasonable; however, it should be noted that the airspeed for the maximum climb angle is very close to the stall speed, thus it is not recommended to use it in practice. In reality, due to safety reasons, climbing should be carried out at an airspeed of about $22 \mathrm{~m} / \mathrm{s}$;

- maximum airspeed for level flight equals about $35 \mathrm{~m} / \mathrm{s}(125 \mathrm{~km} / \mathrm{h})$ at sea level and drops to $33 \mathrm{~m} / \mathrm{s}(119 \mathrm{~m} / \mathrm{s})$ at an altitude of $1000 \mathrm{~m}$.

\section{Range and endurance}

Similarly to the determination of airplane climb performance, the evaluation of the maximum flight duration is one of the most important tasks during preparation for flight tests, since it gives a brief insight into what type of tests and how many trials can be performed during a single flight. This is especially relevant considering electric propulsion systems, as in modern batteries the amount of energy is still lower than that accumulated in fuel. In order to determine the energy accumulated in a single ANR26650M1-B cell more precisely than shown in Table 2, Figure 11 (ANR26650M1-B cell datasheet) was used.

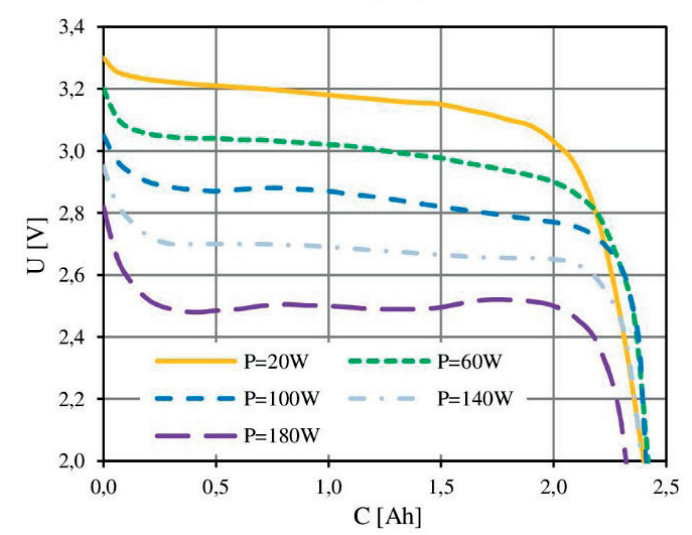

Fig. 11. ANR26650M1-B LiFe cell constant power discharge characteristics

As illustrated above, cell discharge characteristics vary significantly with discharge power, so in the beginning, the engine's electrical power in cruise conditions was evaluated. Based on Figure 8, the power required for level flight with an airspeed of $25 \mathrm{~m} / \mathrm{s}$ was determined as: $\mathrm{P}_{\mathrm{R}}=590 \mathrm{~W}$. According to Figure 6, the propulsion unit efficiency for cruise airspeed equals $\eta=0.635$, thus electric power can be calculated with the use of the equation below:

$$
P_{e}=\frac{P_{R}}{\eta} .
$$

From this we get that $P_{e}=930 \mathrm{~W}$, thus the power of a single cell is: $930 / 48=19.3 \mathrm{~W}$. This means that compliance with the characteristics for $20 \mathrm{~W}$ (orange) is suitable. After the assumption that the cell voltage should not drop below $2.8 \mathrm{~V}$, the amount of energy that can be used from a single cell is given by the following integral:

$$
E_{C}=\int_{0}^{C=2.2 A h} U d C,
$$

to put it simply, this is the area below the $20 \mathrm{~W}$ curve in the range of 0-2.2 Ah and equals: $E_{1}=6.91 \mathrm{Wh}$. Thus, the total energy available from the 48 cell battery is:

$$
E=48 E_{C}=332 W h .
$$

In general, this is an unexceedable limit of energy that can be redistributed to the following mission phases.

\subsection{Take-off}

The aeroplane is designed to use a typical method of take-off, thus for simplicity, it was assumed that this stage consists only of run and lasts until the moment when take-off airspeed, $V_{T O}$, is achieved. The take-off distance and duration can be estimated with the use of the following equations, respectively (Fiszdon 1961):

$$
L_{1}=\frac{W}{2 g} \frac{V_{T O}^{2}}{F_{T O}}\left(1-\frac{1}{2} \frac{F_{0}-F_{T O}}{F_{T O}}\right) ;
$$




$$
t_{1}=\frac{W}{2 g} \frac{V_{T O}}{F_{0}} \frac{1}{\sqrt{1-\frac{F_{T O}}{F_{0}}}} \ln \frac{1+\sqrt{1-F_{T O} / F_{0}}}{1-\sqrt{1-F_{T O} / F_{0}}},
$$

where:

- $V_{T O}$ is the assumed take-off speed, $20 \mathrm{~m} / \mathrm{s}$;

$-F_{0}=T_{0}-\mu W$ is the accelerating force at the beginning of a run;

$-F_{T O}=T_{0}-D_{T O}$ is the accelerating force at the end of a run;

- $D_{T O}$ is the drag force at the take-off configuration and an airspeed of $20 \mathrm{~m} / \mathrm{s}$;

$-\mu$ is the assumed friction coefficient for a dry concrete runway, 0.04 .

After solving the equations provided, the following values were achieved:

$L_{1}=51 \mathrm{~m}$ and $t_{1}=6 \mathrm{~s}$.

Then, the energy used for take-off is given by equation (12):

$$
E_{1}=\int_{0}^{t_{1}} P_{e} d t
$$

It was simplified after taking a conservative assumption that the motor power is constant throughout the run and equals: $P_{e}=3590 \mathrm{~W}$ (according to Fig. 6). Thus:

$$
E_{1}=P_{e \max } \cdot t_{1}=5.7 W h .
$$

\subsection{Climb phase}

This is the phase that follows the take-off and is continued until the cruise ceiling is reached. It is usually carried out at maximum climb rate airspeed, which in this case is equal to $22 \mathrm{~m} / \mathrm{s}$. After setting the ceiling to $h=200 \mathrm{~m}$ and climb rate to $w_{h}=5.2 \mathrm{~m} / \mathrm{s}$ (a conservative assumption for $h=200 \mathrm{~m}$, see Fig. 9), the time of climb equals:

$$
t_{2}=\frac{h}{w_{h}}=38 s .
$$

Then, according to Figure $6, P_{\text {eclimb }}=3000 \mathrm{~W}$, thus:

$$
E_{2}=P_{\text {eclimb }} \cdot t_{2}=32.1 W h \text {. }
$$

\subsection{Go-around procedure}

This phase is optional, so it is not carried out during every flight. However, it must be taken into account during mission planning in case of unpredictable situations, such as runway traffic, unsuccessful landing approach due to any reasons, and so on. It was assumed that after the decision to abort the landing the aeroplane should climb up to about $\Delta h=50 \mathrm{~m}$ and make a $360 \mathrm{deg}$ turn with a radius of about $R=200 \mathrm{~m}$ in order to return to landing path. Climbing is performed at an airspeed of $22 \mathrm{~m} / \mathrm{s}$, and, with a climb rate of at least $\mathrm{w}_{\mathrm{GA}}=3 \mathrm{~m} / \mathrm{s}$, the turn airspeed equals $22 \mathrm{~m} / \mathrm{s}$ as well. Then, the energy consumed for climb equals:

$$
E_{3^{\prime}}=\frac{w_{G A}}{w_{h}} P_{\text {eclimb }} \cdot \frac{\Delta h}{w_{G A}} .
$$

If $P_{\text {eclimb }}=3000 \mathrm{~W}$ (according to Fig. 6), then:

$E_{3}=8 \mathrm{Wh}$.

Additionally, the energy consumed for turn equals approximately:

$$
E_{3^{\prime \prime}}=\frac{P_{R}}{\eta} \frac{2 \pi R}{V},
$$

where $P_{R}=440 \mathrm{~W}$, and is the power required for a steady level flight at $h=200 \mathrm{~m}$ and at an airspeed of $V=22$ $\mathrm{m} / \mathrm{s}$ (Fig. 8), while $\eta=0.57$, and is the propulsion unit's efficiency (Fig. 6).

$E_{3}=12.2 \mathrm{Wh}$

Then:

$$
E_{3}=E_{3^{\prime}}+E_{3^{\prime \prime}}=20.2 \mathrm{Wh} .
$$

\subsection{Descending and landing}

The landing phase will be completed by using the undercarriage, typically to general aviation aeroplanes, so it is reasonable to claim that the engine is turned-off during this phase, so it can be written that:

$$
E_{4}=0 \mathrm{Wh} \text {. }
$$

It is possible that just before touch down, a small engine impulse would be required, but it is difficult to predict and insignificant in this analysis.

\subsection{Cruise/tests phase}

This is the phase when the main task of the mission is performed, such as a simple cruise, reconnaissance, stability or performance tests, etc. This phase is intentionally discussed in the end, since it is only now possible to estimate the amount of energy available for this phase:

$$
E_{4}=E-E_{1}-E_{2}-E_{3}-E_{4}=274 W h \text {. }
$$

The simplest mission type is a single cruise, for which the endurance is given by Equation (20):

$$
t_{4}=E_{4} \frac{\eta}{P_{R}}
$$

where $\eta$ is the propulsion unit efficiency taken from Figure 6 and $P_{R}$ is the power required for a steady level flight determined with the use of Figure 8 . Then, the range can be calculated as:

$$
L_{4}=t_{4} \cdot V \text {. }
$$

The results of endurance and range calculations for different airspeeds, from a minimum (stall) to a maximum level flight at $200 \mathrm{~m}$ are shown in Figure 12. As shown, the maximum endurance equals about $22.5 \mathrm{~min}$, when flying with an economic airspeed of $19.3 \mathrm{~m} / \mathrm{s}$, while the maximum range can be achieved for an optimal airspeed of $22 \mathrm{~m} / \mathrm{s}$ and equals approximately $28 \mathrm{~km}$. This 


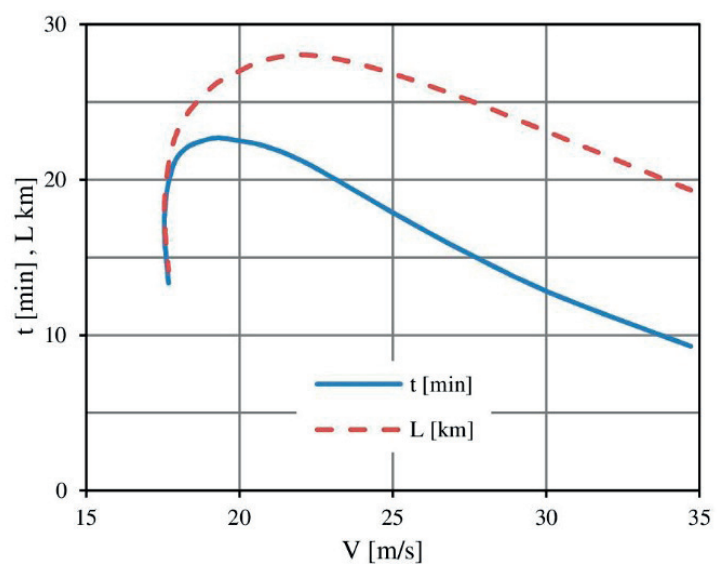

Fig. 12. Maximum range and endurance versus airspeed for a simple cruise mission

means that the planned cruise speed $\left(V_{c r}=25 \mathrm{~m} / \mathrm{s}\right)$ was overestimated. It could have been due to the uncertainty in the drag estimation and the complexity of the propulsion system integration.

It has to be noted, that these are theoretical values, based on the assumption that the whole mission is performed in a calm atmosphere, with no disturbances or wind. In reality, both endurance as well as range can be significantly reduced, depending on the atmospheric conditions and the pilot's skills. As stated previously, this phase may also consist of a set of test maneuvers; however, since it requires a more detailed description, it will be covered in the next paragraph.

\section{Mission profile and test planning}

Since the aeroplane is intended to act as a flight demonstrator, it is supposed to carry out different performance and stability tests. The aeroplane ought to be able to carry out a set of tests during a single flight within reasonable time frames. This requirement is strongly connected with the flight duration, since several samples of a test mission with great attention to flight duration and energy available in the battery will be shown.

\subsection{Longitudinal stability tests}

In this set of tests, phugoid and short period oscillations are to be investigated for different airspeeds. A phugoid test should last at least twice as long as the time constant obtained from the numerical simulation (Lis 2014), i.e. not less than $30 \mathrm{~s}$. The reason for it is that at least two complete oscillations are needed to determine the time constant and the damping ratio with satisfactory accuracy. The sample plan of a single test loop is shown in Figure 13.

Before the test, the aeroplane should be stabilized in a straight, steady level flight within approximately 5 seconds and after that the test can be performed. Next,

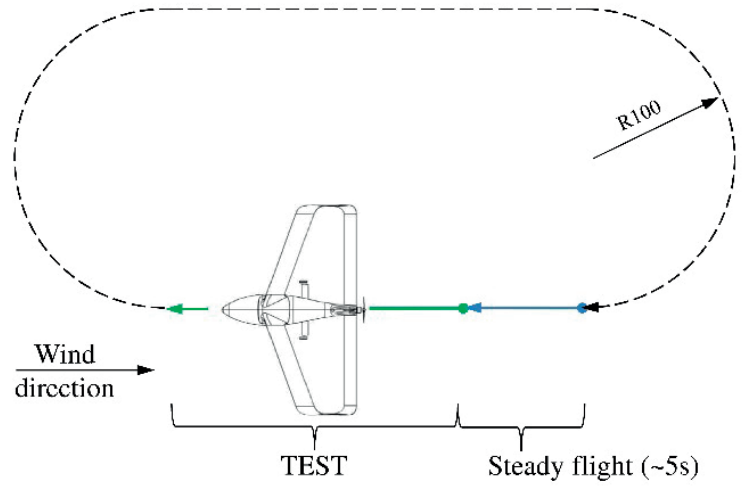

Fig. 13. A single test loop plan

the pilot makes a $180^{\circ}$ turn, keeps flying in the opposite direction to the test flight and, once again, makes a turn to get back to the starting point. This test should be performed at cruise airspeed $(25 \mathrm{~m} / \mathrm{s})$ and repeated for landing airspeed with flaps fully down $(20 \mathrm{~m} / \mathrm{s})$. The altitude should be at about 200 meters.

Similar tests should be carried out to investigate short period oscillations. The major difference is that it is sufficient, if test lasts about 10 seconds. The test for the two airspeeds and flap configurations ought to be performed as described above.

\subsection{Lateral stability tests}

The most important tests for the determination of lateral stability are dutch roll and spiral tests. Both tests can be performed in a way similar to the longitudinal short period oscillation test. The approximate 10 second duration of the tests is supposed to be adequate. The only difference lies in the excitation method and the parameters measured.

In the case of the spiral mode test, it is essential to climb up to approximately 300 meters, since the altitude lost during this test is expected to be significant. For this reason, the single test loop has to be modified, i.e. after the first turn, climbing follows, in order to reach the starting altitude before the second turn. Because of the asymmetry generated by the propulsion unit torque, the spiral test should be performed in both, left and right directions.

Table 3 shows three sample mission types: a single cruise, a longitudinal stability test and a lateral stability test mission. The estimated duration of and the energy consumed in each mission was presented for an assumed number of tests. As shown in Table 3, during each stability test mission, every trial can be performed three times. It was a conservative assumption to leave a certain energy reserve $(\sim 10 \%)$ in the batteries since the calculations provided are rough. Nevertheless, the real energy consumption should be verified during first test flights and a proper energy reserve ought to be determined. 
Table 3. Three exemplary mission types with the estimated time and energy required for each test

\begin{tabular}{|c|c|c|c|c|}
\hline SINGLE CRUISE & \multicolumn{2}{|c|}{ LONGITUDINAL STABILITY TESTS } & \multicolumn{2}{|c|}{ LATERAL STABILITY TESTS } \\
\hline \multicolumn{5}{|c|}{ Take-off Duration 6 s Energy: $5.7 \mathrm{Wh}$} \\
\hline \multicolumn{5}{|c|}{ Climb Duration: 38 s Energy: $32.1 \mathrm{Wh}$} \\
\hline \multirow{2}{*}{$\begin{array}{c}\text { Cruise } \\
\text { Duration: } \\
\text { 557-1361 s } \\
\text { Energy: } 274 \mathrm{Wh}\end{array}$} & $\begin{array}{c}\text { Phugoid } \\
\text { Duration: } 95 \mathrm{~s} \\
\text { Energy: } 24.6 \mathrm{Wh} \\
\text { Repetitions: } 3\end{array}$ & $\begin{array}{c}\text { Phugoid } \\
\text { (flap +20 deg } \\
\text { down) } \\
\text { Duration: } 76 \mathrm{~s} \\
\text { Energy: } 24.9 \mathrm{Wh} \\
\text { Repetitions: } 3\end{array}$ & $\begin{array}{c}\text { Dutch roll } \\
\text { Duration: } 55 \mathrm{~s} \\
\text { Energy: } 14.2 \mathrm{Wh} \\
\text { Repetitions: } 3\end{array}$ & $\begin{array}{c}\text { Dutch roll } \\
\text { (flap }+20 \mathrm{deg} \\
\text { down) } \\
\text { Duration: } 61 \mathrm{~s} \\
\text { Energy: } 15.4 \mathrm{Wh} \\
\text { Repetitions: } 3\end{array}$ \\
\hline & $\begin{array}{c}\text { Short period } \\
\text { Duration: } 55 \mathrm{~s} \\
\text { Energy: } 14.2 \mathrm{Wh} \\
\text { Repetitions: } 3\end{array}$ & $\begin{array}{c}\text { Short period } \\
\text { (flap +20 deg } \\
\text { down) } \\
\text { Duration: } 61 \mathrm{~s} \\
\text { Energy: } 15.4 \mathrm{Wh} \\
\text { Repetitions: } 3 \\
\end{array}$ & $\begin{array}{c}\text { Spiral } \\
\text { Duration: } 63 \mathrm{~s} \\
\text { Energy: } 27.5 \mathrm{Wh} \\
\text { Repetitions: } 3\end{array}$ & $\begin{array}{c}\text { Spiral } \\
\text { (flap +20 deg } \\
\text { down) } \\
\text { Duration: } 66 \mathrm{~s} \\
\text { Energy: } 26.3 \mathrm{Wh} \\
\text { Repetitions: } 3 \\
\end{array}$ \\
\hline \multicolumn{5}{|c|}{ Go-around procedure Duration [s]: 74 Energy [Wh]: 20.3} \\
\hline \multicolumn{5}{|c|}{ Descending and landing Duration [s]: 90 Energy [Wh]: 0} \\
\hline $\begin{array}{l}\text { Total duration: } 12.7-26.1 \mathrm{~min} \\
\text { Total energy: } 332 \mathrm{Wh}\end{array}$ & $\begin{array}{l}\text { Total dura } \\
\text { Total ene }\end{array}$ & $\begin{array}{l}n: 17.9 \mathrm{~min} \\
: 295 \mathrm{Wh}\end{array}$ & $\begin{array}{r}\text { Total dura } \\
\text { Total ene }\end{array}$ & $\begin{array}{l}\text { n: } 15.7 \mathrm{~min} \\
: 308 \mathrm{Wh}\end{array}$ \\
\hline
\end{tabular}

Furthermore, three repetitions for each test seem reasonable for a single flight as it is desirable to review the data obtained and to introduce modifications into the mission plan before the next flight is to be performed. This is done since, due to weather conditions and other autonomous reasons, not every mission can provide valuable data records.

\section{Conclusions}

The results of work presented in this paper show that the aeroplane possesses positive performance properties. The estimated climb rate values for several flight altitudes confirm that the propulsion unit was chosen properly, so there is no need to look for a different one. Similarly, the calculation of flight duration revealed that it is sufficient to perform the basic flight tests; however, it has to be verified in real-life conditions, as no safety margins have been introduced. The proposed mission types for the evaluation of airplane stability qualities prove that there is enough time to repeat each test three times, which is adequate to collect the required data. In spite of the fact that the analyses showed that the optimum airspeed was overestimated during the design phase, it has no influence on test safety, but should be verified during first flights. Even though, the analysis methods used above are not very precise, it can be said that the analytical results shown above are mostly consistent with those obtained during the first flights performed so far.

All of the above and the positive stability properties described in (Lis 2014) show the aeroplane's airworthiness and usefulness as a flight demonstrator.

\section{Acknowledgements}

The authors acknowledge the support of The National Centre for Research and Development that founded the grant No. PBS/A6/14/2012 under which the work described herein has been done.

\section{References}

ANR26650M1-B cell datasheet [online], [cited 15 September 2014]. Available from Internet: http://www.batteryspace. com/prod-specs/6610.pdf

Bogdanski, K.; Rodzewicz, M. 2014. Integration of the propulsion system with MOSUPS aircraft, in 11th International Seminar Research and Education in Aircraft Design, 15-17 October 2014, Vilnius, Lithuania.

Fiszdon, W. 1961. Mechanika lotu. Czesc 1. $2^{\text {nd }}$ ed. Warsaw: Panstwowe Wydawnictwo Naukowe, 127-193.

Foong, K. E.; Djojodihardjo, H. 2012. Conceptual design and aerodynamic study of joined-wing business jet aircraft, in Proceedings of the 28th Congress of the International Council of the Aeronautical Sciences, 23-28 September 2012, Brisbane, Australia.

Frediani, A. 2005. The Prandtl wing, in VKI lecture series on Innovative Configurations and Advanced Concepts for Future Civil Aircraft, 6-10 June 2005, Rhode-St-Genese, Belgium.

Galinski, C.; Goraj, Z. 2004. Experimental and numerical results obtained for a scaled RPV and a full size aircraft, Aircraft Engineering and Aerospace Technology 76(3): 305-313. http://dx.doi.org/10.1108/00022660410536041

Galinski, C.; Hajduk, J.; Kalinowski, M., et al. 2014. Inverted joined wing scaled demonstrator programme, in Proceedings of the 29th Congress of the International Council of the Aeronautical Sciences, 7-12 September 2014, Petersburg, Russia.

Galinski, C.; Hajduk, J.; Kalinowski, M., et al. 2013. The concept of the joined wing scaled demonstrator programme, in Proceedings of the 4th Council of European Aerospace Societies conference, 19-20 September 2013, Linkoping, Sweden. 244-253. 
Goraj, Z.; Kittmann, K.; Voit-Nitschmann, R., et al. 2012. Design and integration of Flexi-Bird - a low cost sub-scale research aircraft for safety and environmental issues, in Proceedings of the 28th Congress of the International Council of the Aeronautical Sciences, 23-28 September 2012, Brisbane, Australia.

Goraj, Z.; Kulicki, P.; Lasek, M. 1997. Aircraft stability analysis for strongly coupled aerodynamic configuration, Journal of Theoretical and Applied Mechanics 35(1): 137-158.

Goraj, Z.; Szender, M. 2004a. Badania modelu samolotu w locie na duzych katach natarcia, in Proceedings of the VI Konferencja Metody i Technika Badan Statkow Powietrznych w Locie, 15-18 June 2004, Mragowo, Poland. 143-153.

Goraj, Z.; Szender, M. 2004b. Techniques and critical technologies applied for small and mini UAVs. State of the art and development perspectives, Transactions of the Institute of Aviation (183): 41-49.

Jemitola, P. O.; Fielding, J. P. 2012. Box wing aircraft conceptual design, in Proceedings of the 28th Congress of the International Council of the Aeronautical Sciences, 23-28 September 2012, Brisbane, Australia.

Kroo, I. 2005. Nonplanar wing concepts for increased aircraft efficiency, in VKI lecture series on Innovative Configurations and Advanced Concepts for Future Civil Aircraft, 6-10 June 2005, Rhode-St-Genese, Belgium.

Lis, M.; Dziubinski, A.; Galinski, C., et al. 2014. Predicted flight characteristics of the inverted joined wing scaled demonstrator, in Proceedings of the 29th Congress of the International Council of the Aeronautical Sciences, 7-12 September 2014, Petersburg, Russia.

Mamla, P.; Galinski, C. 2009. Basic induced drag study of the joined-wing aircraft, Journal of Aircraft 46(4): 1438-1440. http://dx.doi.org/10.2514/1.42084

Munk, M. 1923. The minimum induced drag of aerofoils. NACA Report 121.

Perkins, C. D.; Hage, R. E. 1949. Airplane performance, stability and control. New York: Wiley \& Sons, 155-158.

Prandtl, L. 1924. Induced drag of multiplanes. NACA TN 182.

Schiktanz, D. 2011. Conceptual design of a medium range box wing aircraft: MSc thesis. Department of Automotive and Aerospace Engineering, Hamburg University of Applied Sciences, Hamburg, Germany.

Wolkovitch, J. 1976. Joined wing aircraft. U.S. Patent 3.942.747.

Wolkovitch, J. 1986. The joined wing - an overview, Journal of Aircraft 23(3): 161-178. http://dx.doi.org/10.2514/3.45285

\section{Copyright statement}

The authors confirm that they, and/or their company or organization, hold copyright on all of the original material included in this paper. The authors also confirm that they have obtained permission, from the copyright holder of any third party material included in this paper, to publish it as part of their paper. The authors confirm that they give permission, or have obtained permission from the copyright holder of this paper, for the publication and distribution of this paper as part of the READ 2014 proceedings or as individual off-prints from the proceedings. 